\section{Innate immune cells, major protagonists of sickle cell disease pathophysiology}

\author{
Slimane Allali, ${ }^{1,2,3}$ Thiago Trovati Maciel, ${ }^{2,3}$ Olivier Hermine ${ }^{2,3,4}$ and Mariane de \\ Montalembert ${ }^{1,3}$
}

${ }^{1}$ Department of General Pediatrics and Pediatric Infectious Diseases, Reference Center for Sickle Cell Disease, Necker Hospital for Sick Children, Assistance Publique - Hôpitaux de Paris (AP-HP), Paris Descartes University, Paris; ${ }^{2}$ Laboratory of Cellular and Molecular Mechanisms of Hematological Disorders and Therapeutical Implications, Paris Descartes - Sorbonne Paris Cite University, Imagine Institute, Inserm U1163, Paris; ${ }^{3}$ Laboratory of Excellence GR-Ex, Paris and ${ }^{4}$ Department of Hematology, Necker Hospital for Sick Children, AP-HP, Paris Descartes University, Paris, France

\section{ABSTRACT}

S ickle cell disease (SCD), considered the most common monogenic disease worldwide, is a severe hemoglobin disorder. Although the genetic and molecular bases have long been characterized, the pathophysiology remains incompletely elucidated and therapeutic options are limited. It has been increasingly suggested that innate immune cells, including monocytes, neutrophils, invariant natural killer T cells, platelets and mast cells, have a role in promoting inflammation, adhesion and pain in SCD. Here we provide a thorough review of the involvement of these novel, major protagonists in SCD pathophysiology, highlighting recent evidence for innovative therapeutic perspectives.

\section{Introduction}

Sickle cell disease (SCD) is a life-threatening genetic hemoglobin disorder, characterized by chronic hemolytic anemia, recurrent painful vaso-occlusive events and progressive multiple organ damage. ${ }^{1}$ It is a global health issue, affecting millions of people worldwide, and its incidence is expected to increase to 400,000 neonates born per year by $2050 .^{2}$ The genetic and molecular bases are fully characterized: SCD originates from a single nucleotide mutation of the $\beta$-globin gene, leading to polymerization of the abnormal deoxygenated hemoglobin $\mathrm{S}(\mathrm{HbS})$, which results in obstruction of small vessels by sickle-shaped red blood cells (RBC). However, in the last two decades, the pathophysiology has been found to be much more complex than originally thought, involving many factors other than RBC. Innate immune cells include circulating cells, such as monocytes, dendritic cells, neutrophils, eosinophils, basophils, natural killer (NK) cells, invariant natural killer T (iNKT) cells and platelets, along with tissue-resident macrophages and mast cells.

Here we review the evidence for a contribution of innate immune cells to the pathophysiology of SCD.

\section{Monocytes}

Monocytes have long been considered important in SCD pathophysiology. Monocytosis is common in SCD and is positively correlated with markers of hemolysis and negatively with hemoglobin level. ${ }^{3}$ The absolute monocyte count is lower in SCD children being treated with hydroxyurea than in those not receiving such treatment, which may reflect another positive effect of hydroxyurea in SCD. ${ }^{4}$ In vitro, the interaction of RBC from SCD patients with cultured human umbilical vein endothelial cells was responsible for enhanced cellular oxidant stress, resulting in a two-fold increase in transendothelial migration of human peripheral blood monocytes. ${ }^{5}$ More importantly, monocytes from SCD patients display an activated profile, with increased expression of $\mathrm{CD} 11 \mathrm{~b}$ on their surface and increased production of interleukin (IL)-1 $\beta$ and tumor necrosis factor (TNF)- $\alpha$ as compared with healthy control monocytes. ${ }^{6.8}$ Upregulation of CD1 molecules on monocytes has been described, reflecting the activated status of these cells. ${ }^{9}$ Mononuclear cells

\section{Ferrata Storti Foundation}

Haematologica 2020

Volume 105(2):273-283

\section{Correspondence:}

SLIMANE ALLALI

slimane.allali@aphp.fr

\section{MARIANE DE MONTALEMBERT}

mariane.demontal@nck.aphp.fr

Received: June 18, 2019.

Accepted: September 26, 2019.

Pre-published: January 9, 2020.

doi:10.3324/haematol.2019.229989

Check the online version for the most updated information on this article, online supplements, and information on authorship \& disclosures: www.haematologica.org/content/105/2/273

\section{(C)2020 Ferrata Storti Foundation}

Material published in Haematologica is covered by copyright. All rights are reserved to the Ferrata Storti Foundation. Use of published material is allowed under the following terms and conditions:

https://creativecommons.org/licenses/by-nc/4.0/legalcode. Copies of published material are allowed for personal or internal use. Sharing published material for non-commercial purposes is subject to the following conditions: https://creativecommons.org/licenses/by-nc/4.0/legalcode, sect. 3. Reproducing and sharing published material for commercial purposes is not allowed without permission in writing from the publisher. 
from SCD patients also show increased production of superoxide anions, which may be explained by the upregulation of NADPH oxidase components in SCD monocytes. ${ }^{10,11}$ Another sign of SCD monocyte activation is increased numbers of circulating tissue factor-positive monocytes, which contribute to the coagulation abnormalities observed in SCD patients. ${ }^{12}$ Tissue factor expression on monocytes from SCD children was found to be positively correlated with pain rate, C-reactive protein level and reticulocyte percentage and negatively with hemoglobin concentration, suggesting a role for hemolysis and inflammation in SCD monocyte activation. ${ }^{13}$

In turn, as compared with normal monocytes, activated monocytes from SCD patients can activate endothelial cells via the nuclear factor (NF)- $\kappa \mathrm{B}$ pathway, resulting in enhanced expression of E-selectin, intracellular adhesion molecule 1 (ICAM-1) and vascular cell adhesion molecule 1 (VCAM-1). ${ }^{6}$ Endothelial activation is mediated by IL-1 $\beta$ and TNF- $\alpha$, produced by SCD monocytes, as demonstrated by its abrogation with antibodies targeting these two pro-inflammatory cytokines. ${ }^{6}$ Recently, a prominent role for the monocyte-TNF- $\alpha$-endothelial activation axis was reported in transgenic sickle mice, with more global benefits from the TNF- $\alpha$ blockers etanercept and infliximab than from the IL-1 $\beta$ blocker anakinra. ${ }^{14}$

Regarding the suspected mechanisms of monocyte activation, a role for hypoxemia was first suggested by a negative correlation between nocturnal oxygen saturation and CD11b expression in monocytes from children with SCD. ${ }^{8}$ The amount of circulating platelet-monocyte aggregates has been reported to be increased in SCD patients as compared with that in healthy controls, suggesting a possible activation of monocytes by platelets, which are known to be activated in SCD. In whole blood from SCD patients, the formation of platelet-monocyte aggregates is mediated by a $\mathrm{P}$-selectin/P-selectin glycoprotein ligand 1 (PSGL-1) interaction, which may activate monocytes. ${ }^{15}$ Other interesting results came from the demonstration that placental growth factor (PlGF) released by $\mathrm{RBC}$ can activate monocytes from SCD patients, resulting in increased production of several pro-inflammatory cytokines and chemokines, including IL-1 $\beta$, TNF- $\alpha$, monocyte chemoattractant protein 1 (MCP-1), macrophage inflammatory protein-1 $\beta$ (MIP-1 $\beta)$, IL-8 and vascular endothelial growth factor (VEGF), via the activation of Flt-1 and the PI3K/AKT and ERK-1/2 pathways. ${ }^{16,17}$ Placental growth factor plasma levels are higher in SCD patients than in healthy controls and positively correlated with anemia, pulmonary hypertension and the incidence of vaso-occlusive crises (VOC). ${ }^{17,18}$ Monocyte activation may also be mediated by interactions with sickle RBC since epinephrine-activated sickle RBC can promote monocyte adhesion to human umbilical vein endothelial cells. ${ }^{19}$ As demonstrated in vitro and in whole blood from SCD patients, plasma fibronectin creates a bridge between two integrin $\alpha 4 \beta 1$ molecules on monocytes and on SS reticulocytes, mediating the formation of monocyte-reticulocyte aggregates. ${ }^{15}$ The interaction between $\alpha 4 \beta 1$ on monocytes and Lutheran/basal cell adhesion molecule (Lu/BCAM) on RBC may contribute to the formation of monocyte-RBC aggregates. ${ }^{20} \mathrm{~A}$ role for heme, released by intravascular hemolysis, in inducing monocyte activation could be suspected, but contrary to lipopolysaccharide, heme was recently found to be insufficient to induce IL-6 production by monocytes from SCD patients, although it may potentiate the effects of lipopolysaccharide. ${ }^{21}$

New insights into the role of monocytes in SCD pathophysiology have recently been provided by the description of a patrolling monocyte subset expressing a very high level of heme oxygenase- $1\left(\mathrm{HO}-1^{\text {hi }}\right)$ in SCD patients. ${ }^{22}$ Patrolling monocytes are $\mathrm{CD} 14^{\text {low }} \mathrm{CD} 16^{+}$monocytes able to scavenge cellular debris derived from the damaged vascular endothelium. In vitro, $\mathrm{HO}-1^{\text {hi }}$ expression was induced in patrolling monocytes on co-culture with hemin-treated endothelial cells, and $\mathrm{HO}-1^{\text {hi }}$ cells had higher levels of endothelial cell-derived material than $\mathrm{HO}-1^{\text {low }}$ cells, which suggests that patrolling monocytes take up debris from heme-exposed endothelial cells, resulting in $\mathrm{HO}-1^{\mathrm{hi}}$ expression. ${ }^{22}$ Importantly, mice lacking patrolling monocytes displayed more vascular stasis in the presence of sickle RBC than did control mice and this effect was attenuated by the transfer of patrolling monocytes, which supports a role for these cells in preventing VOC. Among patients on chronic transfusion exchange therapy, those with recent $\mathrm{VOC}$ or a history of recurrent VOC showed the lowest number of $\mathrm{HO}-1^{\text {hi }}$ patrolling monocytes. ${ }^{22}$ Hence, SCD patrolling monocytes may play an important role in scavenging cellular debris derived from heme-exposed endothelial cells, thus reducing the risk of VOC. Patrolling monocytes can also take up endothelial-adherent sickle RBC, especially during VOC, and $\mathrm{HO}-1$ upregulation increases the survival of the patrolling monocytes by counteracting the cytotoxic effects of RBC-engulfed material. ${ }^{23}$ Further investigations are required to determine whether patrolling monocytes in SCD can remove other blood cells attached to the endothelium, such as neutrophils.

The main findings on the involvement of monocytes in SCD pathophysiology are summarized in Figure 1.

\section{Dendritic cells}

Alloimmunization is a major complication of RBC transfusion both in adults and children with SCD, but its pathogenesis remains poorly understood..$^{24}$ A role for dendritic cells in the mechanisms underlying alloimmunization was recently demonstrated in heme-exposed monocyte-derived dendritic cells from alloimmunized SCD patients as compared with non-alloimmunized patients and healthy controls. ${ }^{25}$ In vitro, heme downregulated maturation of monocyte-derived dendritic cells from nonalloimmunized patients and healthy controls, which resulted in inhibited priming of pro-inflammatory CD4+ type $1 \mathrm{~T}$ cells by the dendritic cells. By contrast, in alloimmunized patients, heme did not affect the maturation of dendritic cells or their ability to prime Th1 cells. Hence, the defective anti-inflammatory response to heme in alloimmunized patients may result in alterations in T-cell profile with an increase in pro-inflammatory (Th1) and a decrease in anti-inflammatory (Treg) T-cell subsets. Further investigations are required as they may open new therapeutic perspectives to prevent this potentially lifethreatening complication.

It has also been suggested that dendritic cells may play a role in the pathogenesis of SCD-related orthopedic complications, such as osteonecrosis, osteoporosis and osteopenia, with there being an overexpression of bone morphogenetic protein (BMP)- 6 in monocyte-derived dendritic cells from SCD patients with orthopedic complications as compared with SCD patients without orthopedic complications and healthy controls. ${ }^{26}$ However, further 
investigations are required to confirm the role of dendritic cells and the BMP/SMAD signaling pathway in SCD bone complications.

\section{Neutrophils}

Neutrophils have long been suspected to be involved in the pathophysiology of SCD. The absolute neutrophil count is higher in SCD patients in steady-state than in ethnicity-matched healthy controls and is positively correlated with SCD severity. ${ }^{27}$ A high leukocyte count is also a risk factor for early death, acute chest syndrome (ACS), hemorrhagic stroke and sickle nephropathy. ${ }^{28-31}$ Conversely, decreased neutrophil count may have positive effects, as suggested by a report of an alleviated SCD phenotype in a patient with associated congenital neutropenia who experienced the first episodes of VOC after the introduction of granulocyte colony-stimulating factor (G-CSF) to treat neutropenia. ${ }^{32}$ Thus, G-CSF and granulocytemacrophage colony-stimulating factor (GM-CSF) should be strictly avoided in SCD patients because myeloid growth factors are responsible for VOC and ACS.33,34 Hydroxyurea may have clinical benefit for SCD patients even in the absence of elevated fetal hemoglobin ( $\mathrm{HbF})$ level, but a decrease in neutrophil count is always observed in such cases, and hydroxyurea seems most effective in patients with the greatest reduction in neutrophils. ${ }^{35}$

In addition to these quantitative aspects, several studies have highlighted the activated state of neutrophils from
SCD patients, with increased adhesive properties at baseline and even more during VOC. ${ }^{36,37}$ Clinical manifestations of SCD have been found to be associated with the expression of adhesion molecules on leukocytes. ${ }^{38}$ Hydroxyurea may also benefit SCD patients by suppressing neutrophil activation and correcting the dysregulated expression of adhesion markers on these cells. ${ }^{39,40}$ An important step in understanding the role of neutrophils in SCD pathophysiology was the intravital microscopy demonstration in SCD mice of increased neutrophil adhesion to the endothelium but also to sickle RBC in postcapillary venules. ${ }^{41}$ In this model, mice deficient in endothelial P-selectin and E-selectin displayed defective leukocyte recruitment to the vessel wall and were protected against vaso-occlusion. E-selectin was found to induce a secondary wave of activating signals, resulting in the clustering of activated macrophage-1 antigen (Mac-1) on the leading edge of adherent neutrophils, thereby allowing for the capture of sickle RBC and platelets. Here again, inactivation of E-selectin or Mac-1 prevented neutrophil-RBC and neutrophil-platelet interactions, thereby improving blood flow in the microcirculation and mouse survival. ${ }^{42}$ These findings suggest that interactions between activated endothelium, activated neutrophils, captured sickle RBC and platelets can contribute to decreased blood flow, further accentuating RBC sickling, neutrophil recruitment and tissue ischemia. ${ }^{43}$ In blood samples from SCD patients, studied in microfluidic flow chambers, neutrophils rolling on E-selectin under shear stress were found

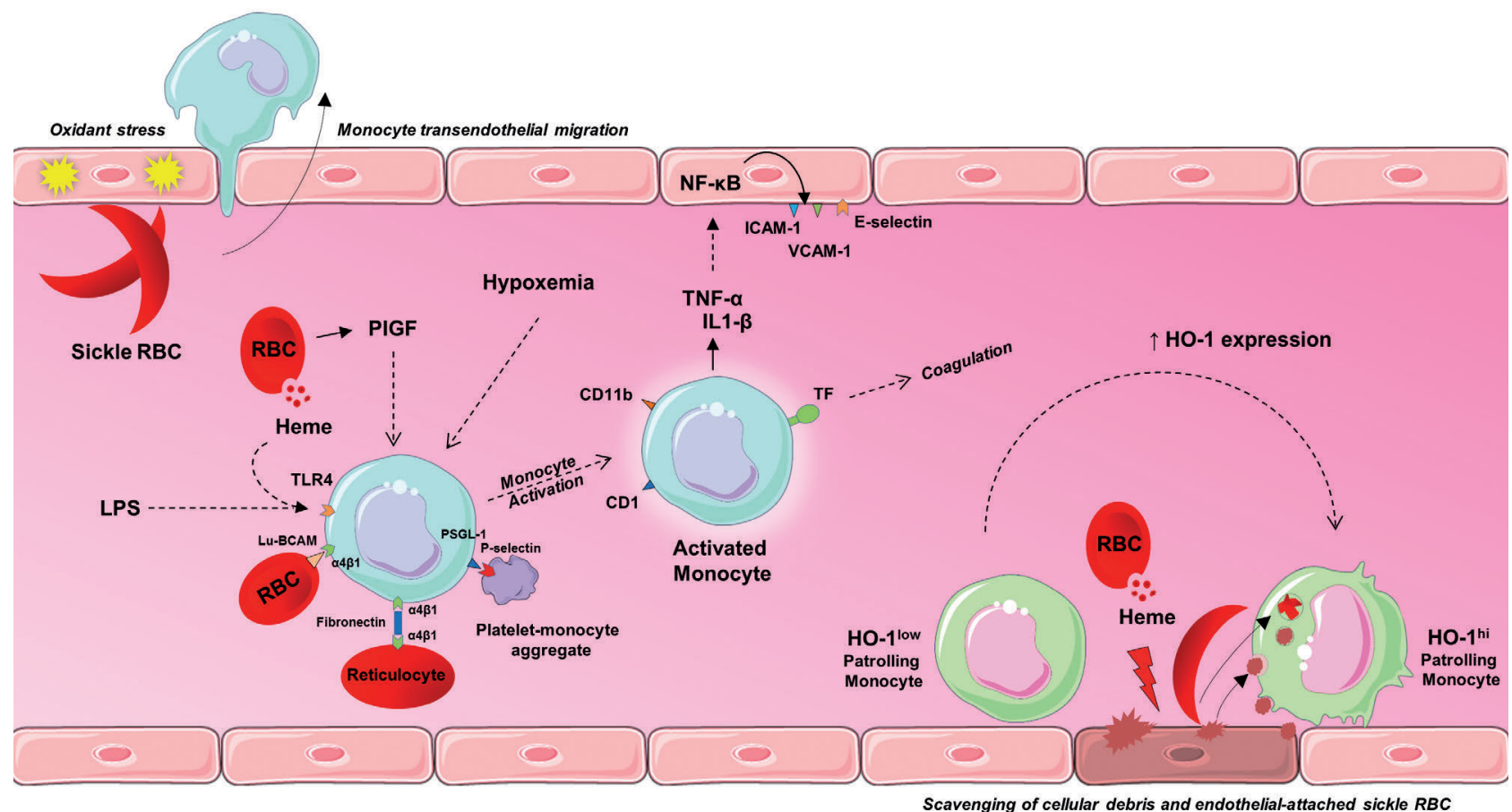

Figure 1. Monocytes in sickle cell disease. Interaction of sickle red blood cells (RBC) with endothelial cells enhances cellular oxidant stress, resulting in increased transendothelial migration of blood monocytes. Suspected mechanisms of monocyte activation in sickle cell disease (SCD) involve hypoxemia, platelet-monocyte aggregates mediated by P-selectin/P-selectin glycoprotein ligand 1 interaction, RBC/reticulocyte-monocyte interactions, placental growth factor released from RBC and co-stimulation of toll-like receptor 4 by heme and lipopolysaccharide. SCD activated monocytes display increased expression of CD1, CD11b and tissue factor on their surfaces, as well as increased production of interleukin-1 $\beta$ and tumor necrosis factor- $\alpha$. In turn, activated monocytes activate endothelial cells through the nuclear factor-кB pathway, resulting in enhanced expression of intercellular adhesion molecule 1, vascular cell adhesion molecule 1 and E-selectin. Patrolling monocytes uptake cellular debris derived from heme-exposed endothelial cells, thus leading to high expression of heme oxygenase-1. Patrolling monocytes also scavenge endothelium-adherent sickle RBC. HO-1: heme oxygenase-1; ICAM-1: intercellular adhesion molecule 1: IL1- $\beta$ : interleukin 1 beta; LPS: lipopolysaccharide; Lu/BCAM: Lutheran/basal cell adhesion molecule; NF-אB: nuclear factor kappa B; PIGF: placental growth factor; PSGL-1: P-selectin glycoprotein ligand 1; TF: tissue factor; TLR4: toll-like receptor 4; TNF- $\alpha$ : tumor necrosis factor alpha; VCAM-1: vascular cell adhesion molecule 1. 
to promote a catch-bond formation between endothelial cell E-selectin and neutrophil L-selectin via tetrasaccharide sialyl Lewis ${ }^{x}\left(\mathrm{sLe}^{\mathrm{x}}\right)$ expressed on L-selectin. ${ }^{44}$ This interaction triggers the activation of high-affinity $\beta_{2}$-integrins, which leads to the formation of shear-resistant bonds with ICAM-1 on inflamed endothelium. Rivipansel, a synthetic pan-selectin antagonist previously shown to improve blood flow and survival in SCD mice, effectively blocks E-selectin recognition of sLe $e^{\mathrm{x}}$ on L-selectin, thereby inhibiting neutrophil adhesion. ${ }^{44,45}$ In a prospective multicenter, randomized, placebo-controlled, double-blind, phase II trial of 76 SCD patients, those in the rivipansel arm showed a non-significant trend toward reduced time to resolution of VOC, and a significant $83 \%$ reduction in mean cumulative intravenous opioid analgesic use. ${ }^{46}$ These results have supported an ongoing phase III trial of rivipansel for SCD VOC (\#NCT02187003). However, the most encouraging results were obtained with another selectin antagonist specifically targeting P-selectin. In a randomized, placebocontrolled, double-blind, phase II trial of 198 SCD patients, treatment with crizanlizumab, a humanized monoclonal antibody directed against P-selectin, significantly reduced the median rate of VOC per year by $45 \% .^{47} \mathrm{~A}$ phase III trial with crizanlizumab is currently in progress (\#NCT03814746) and this drug was recently approved by the US Food and Drug Administration. Among other potential therapeutic agents targeting neutrophils, sevuparin, a novel drug candidate derived from heparin, was found to inhibit adhesion of RBC and leukocytes from SCD patients to human umbilical vein endothelial cells and prevented vaso-occlusion in sickle mice via a multimodal mechanism of action, including P- and L-selectin binding. ${ }^{48,49}$ Therefore, a phase II clinical trial of sevuparin for preventing VOC in SCD patients is ongoing (\#NCT02515838). Intravenous immunoglobulin could also inhibit RBC-neutrophil interactions and neutrophil adhesion to endothelium in sickle mice by inhibiting Mac-1, and no adverse effects were observed in a phase I clinical trial of intravenous immunoglobulin in SCD patients. ${ }^{50} \mathrm{~A}$ phase II trial is currently ongoing (\#NCT01757418).

An important point is that activated platelets as well as endothelial cells express P-selectin, which binds to PSGL-1 on neutrophils, thereby enhancing the formation of platelet-neutrophil aggregates. ${ }^{51}$ In SCD mice, such platelet-neutrophil aggregates have been observed in pulmonary arteriole microemboli, with resolution after selective platelet $\mathrm{P}$-selectin inhibition, which suggests the potential therapeutic interest of targeting P-selectin to prevent ACS. ${ }^{52}$ In the crizanlizumab phase II trial, the ACS rate did not differ between the active-treatment group and the placebo group, but this finding may be explained by the rarity of ACS in this trial, and further studies are needed to determine whether P-selectin blockade prevents ACS in SCD patients. ${ }^{47}$ The platelet-neutrophil association is also mediated by interactions between glycoprotein Ib $\alpha$ (GPIb $\alpha$ ) on platelets and Mac-1 on neutrophils, which is positively regulated by the serine/threonine kinase isoform AKT2 in neutrophils during vascular inflammation. ${ }^{53}$ Here again, specific inhibition of AKT or GPIb $\alpha$ was recently found to attenuate in vitro neutrophil-platelet aggregation in SCD patients' blood, thereby opening new therapeutic perspectives for the prevention and treatment of VOC. . $^{54,55}$

Besides selectin-dependent interactions, adhesion of neutrophils to activated endothelium is modulated by different mediators, such as endothelin-1, with elevated plas- ma levels in SCD patients. In SCD mice, endothelin-1 appears to upregulate TNF- $\alpha$-induced Mac-1 expression on neutrophils. Blocking endothelin receptors, especially the endothelin B receptor, on neutrophils strongly attenuates their recruitment, as demonstrated by intravital microscopy of SCD mice and microfluidic microscopy of SCD human blood. ${ }^{56}$

Another major point is that SCD patients, like SCD mice, display very high proportions of aged neutrophils, which have been positively correlated with endothelial adhesion, Mac-1 expression and the formation of neutrophil extracellular traps (NET). ${ }^{57}$ Neutrophil aging appears to be mediated by microbiota via TLR/Myd88 signaling, and depletion of gut microbiota with antibiotics in SCD mice led to a significant reduction in the number of aged neutrophils, along with improved blood flow and increased survival. A reduced number of aged neutrophils has been reported in SCD patients receiving penicillin, which suggests an additional positive impact of prophylactic antibiotic treatment, mediated by microbiota depletion and reduction in the number of aged neutrophils. ${ }^{57}$ Moreover, bone marrow from SCD mice showed an accumulation of aged neutrophils, possibly impairing osteoblast function; thus, by reducing the number of aged neutrophils, microbiota depletion may improve osteoblast function and bone loss in SCD. ${ }^{58}$

In both SCD mice and patients, elevated plasma heme levels during VOC were found to promote the formation of NET, which are decondensed chromatin with granular enzymes released by activated neutrophils. ${ }^{59}$ In SCD mice, the presence of NET in the lungs contributes to acute lung injury and is associated with hypothermia and death, which can be prevented by clearing NET with DNAse I or by scavenging heme with hemopexin..$^{59}$ Together with heme being able to trigger ACS in SCD mice, these results suggest that NET induced by heme may be involved in the pathogenesis of ACS. ${ }^{6}$ Heme may also contribute to a susceptibility to infections in SCD patients by inducing $\mathrm{HO}$ 1 expression during neutrophilic differentiation, thereby impairing the ability of neutrophils to mount a bactericidal oxidative burst. Indeed, a novel neutrophil progenitor subset expressing high levels of $\mathrm{HO}-1$ was recently identified in the bone marrow of SCD children but not healthy controls. ${ }^{61}$

The main findings on the involvement of neutrophils in SCD pathophysiology are summarized in Figure 2.

\section{Eosinophils}

Independently of parasitic infections, eosinophils are more numerous in steady-state SCD patients than in healthy controls and display an activated phenotype. ${ }^{62,63}$ An increase in absolute eosinophil count appears to result from an increased level of GM-CSF in SCD. ${ }^{64}$ In vitro, adhesion of circulating eosinophils to fibronectin was found to be enhanced in SCD patients and mediated by $\alpha 4 \beta 1$ (VLA-4), lymphocyte function-associated antigen 1 (LFA1) and Mac-1 integrins. ${ }^{62}$ Subsequently, eosinophils from SCD patients were found to demonstrate greater spontaneous migration and release higher levels of peroxidase, eosinophil-derived neurotoxin and reactive oxygen species (ROS) than eosinophils from healthy controls. ${ }^{63}$ Hydroxyurea treatment seems to reduce absolute eosinophil count and eosinophil adhesion and degranulation, which suggests an additional beneficial effect of hydroxyurea in SCD. ${ }^{63}$ 


\section{Basophils}

Few studies have focused on basophils in SCD. In a cohort of 54 SCD patients and 27 healthy controls, basophil count and degranulation, assessed by flow cytometry with the Basotest, were similar in patients and controls. ${ }^{65}$ Further studies are required to determine whether activated basophils could contribute to SCD pathophysiology.

\section{Natural killer cells}

The absolute number of NK cells has been reported to be increased in SCD patients not receiving disease-modifying therapy (hydroxyurea or chronic transfusions) as compared to the numbers in healthy controls and patients on hydroxyurea. ${ }^{4,66}$ Further enhancement during VOC has also been reported. ${ }^{67}$ More importantly, the cytotoxicity of NK cells from SCD patients not on disease-modifying therapy, unlike that of patients receiving hydroxyurea or exchange transfusions, seems significantly increased compared with the cytotoxicity of NK cells from controls. ${ }^{66}$ Because NK cells are capable of graft rejection, this observation of NK cell number and function normalization with hydroxyurea may explain why SCD patients receiving hydroxyurea before bone-marrow transplantation seem to have a reduced risk of graft rejection. ${ }^{6}{ }^{6}$ This finding raises the question of whether it would be beneficial to combine hydroxyurea with chronic transfusion in the pretransplant period, especially with non-myeloablative or HLA-mismatched transplants.

As for iNKT cells, a potential role for NK cells in SCD pulmonary inflammation was described in SCD mice. The mRNA level of adenosine $A_{2 A}$ receptor $\left(A_{2 A} R\right)$ was increased six-fold in pulmonary NK cells from SCD mice as compared with the level in control mice, and activating $\mathrm{A}_{2 \mathrm{~A}} \mathrm{R}$ on NK cells decreased the number of these cells and improved baseline pulmonary function. ${ }^{6}{ }^{9}$

\section{Invariant natural killer T cells}

iNKT cells are known to contribute to hepatic and renal ischemia-reperfusion injury in mice. ${ }^{70}$ Their role has, therefore, been investigated in SCD, which is characterized by repeated microvascular ischemia-reperfusion injury. Lung, liver and spleen iNKT cells were found to be more numerous, more activated and more responsive to hypoxia-reoxygenation in SCD mice than in control mice. ${ }^{71}$ Similarly, SCD patients have shown enhanced levels of circulating iNKT cells, together with increased levels of activation markers and increased interferon (IFN)- $\gamma$ production, especially during VOC. ${ }^{71}$ Treating SCD mice with anti-CD1d antibody to inhibit iNKT-cell activation ameliorated pulmonary dysfunction and decreased pulmonary levels of IFN- $\gamma$ and CXCR3, which suggests an important role of this pathway in SCD pulmonary inflammation. ${ }^{71}$ In

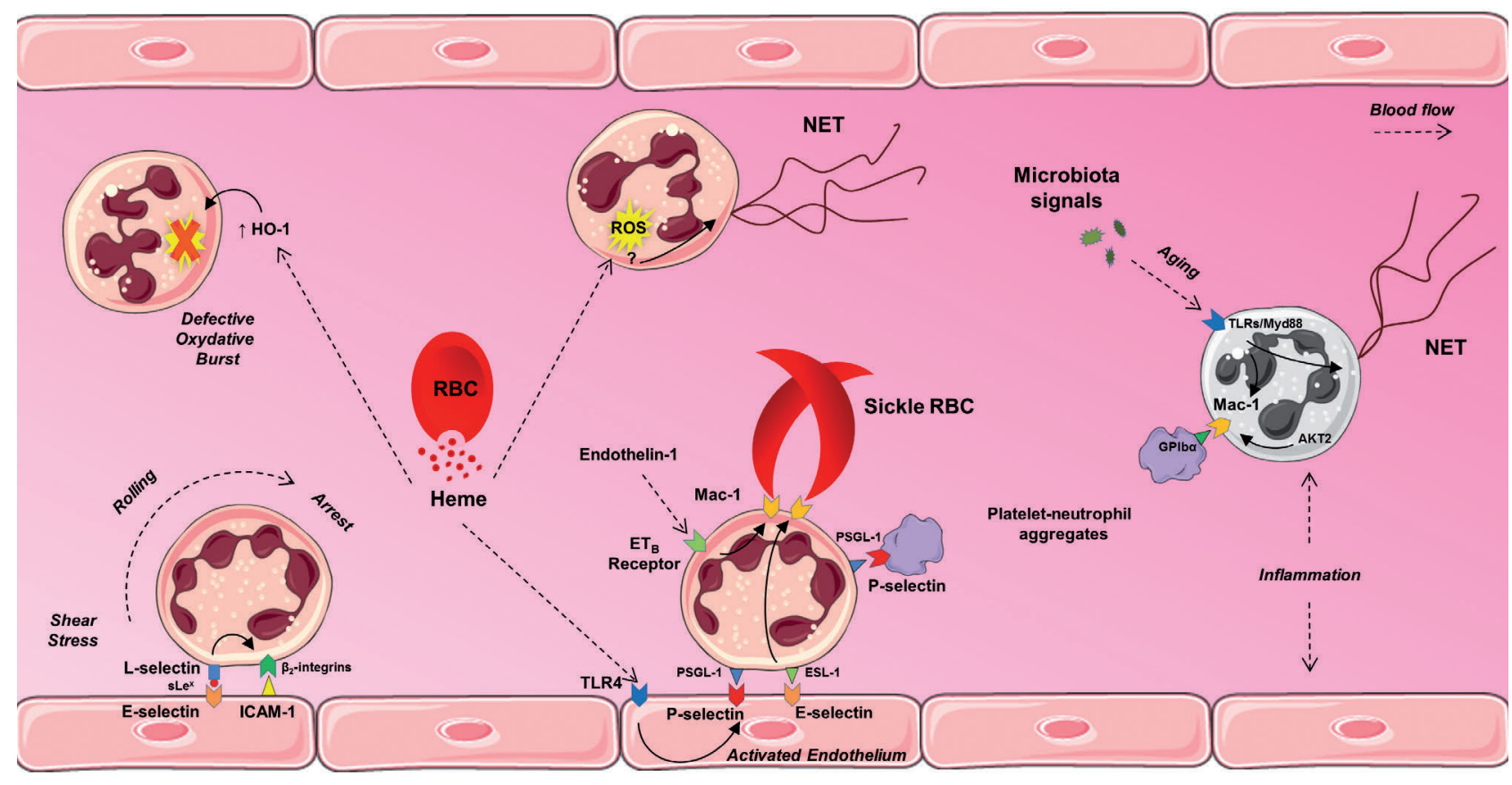

Figure 2. Neutrophils in sickle cell disease. Neutrophils rolling on E-selectin under shear stress promote catch-bond formation between E-selectin and L-selectin via sLe ${ }^{x}$ expressed on L-selectin. This interaction triggers activation of high-affinity $\beta_{2}$-integrins, which leads to shear-resistant bonds with intercellular adhesion molecule 1. Neutrophil adhesion also occurs through interactions between P-selectin glycoprotein ligand 1 (PSGL-1) and endothelial P-selectin, which is upregulated in response to toll-like receptor 4 activation by heme released from red blood cells (RBC). E-selectin induces a secondary wave of activating signals, which leads to the clustering of activated macrophage-1 antigen (Mac-1) on the leading edge of adherent neutrophils, allowing for the capture of sickle RBC. Endothelin-1 promotes Mac-1 expression through the endothelin B receptors on neutrophils. Activated platelets express P-selectin, which binds PSGL-1, thereby enhancing the formation of platelet-neutrophil aggregates. The platelet-neutrophil association is also mediated by interactions between glycoprotein Ib $\alpha$ and Mac-1, which is positively regulated by AKT2 in neutrophils during vascular inflammation. Neutrophil aging is promoted by the microbiota via TLR/Myd88 signaling and is positively correlated with Mac-1 expression and neutrophil extracellular trap (NET) formation. Heme also promotes NET formation, possibly via generation of reactive oxygen species in neutrophils, and induces expression of heme oxygenase-1 during neutrophilic differentiation, thereby impairing the bactericidal oxidative burst. ESL-1: E-selectin ligand1; ET: endothelin; GP: glycoprotein; HO-1: heme oxygenase-1; ICAM-1: intercellular adhesion molecule 1; ROS: reactive oxygen species; TLR: toll-like receptor. 
the same line of evidence, crossing SCD mice with lymphocyte-deficient mice resulted in decreased pulmonary dysfunction, whereas the adoptive transfer of iNKT cells reconstituted injury.

In SCD mice, pulmonary iNKT-cell activation was associated with a nine-fold increase in $A_{2 A} R$ mRNA level as compared with the level in control mice. Treating SCD mice with an $A_{2 A} R$ agonist improved pulmonary inflammation and prevented further hypoxia-reoxygenationinduced lung injury by inhibiting iNKT-cell activation. ${ }^{69}$ In SCD patients, $\mathrm{A}_{2 \mathrm{~A}} \mathrm{R}$ was induced during VOC in $\mathrm{CD} 4^{+}$but not CD4 iNKT cells. ${ }^{72}$ This induction may serve to inhibit iNKT-cell activation over time in a counter-regulatory mechanism, thereby limiting the extent of the inflammatory immune response. $A_{2 A} R$ transcription seems to be induced by NF- $\kappa \mathrm{B}$ activation because the use of NF- $\kappa \mathrm{B}$ inhibitors in cultured human iNKT cells blocked the induction of $\mathrm{A}_{2 \mathrm{~A}} \mathrm{R}$ mRNA and protein. ${ }^{72}$ Furthermore, iNKT cells from SCD patients showed concomitant high expression of $A_{2 A} R$ and CD39, the ecto-ATPase that converts ATP and ADP to AMP, thereby resulting in increased adenosine production, which limits iNKT-cell activation. ${ }^{73}$ In a phase I trial of the $A_{2 A} R$ agonist regadenoson in 27 adult SCD patients, iNKT-cell activation, measured by phospho-NF- $\kappa B$, IFN- $\gamma$ and $A_{2 A} R$ expression, was increased in patients as compared with controls and during VOC as compared with steady-state. ${ }^{74}$ A 24-hour infusion of regadenoson during $\mathrm{VOC}$ decreased the activation of
iNKT cells by $50 \%$, to levels similar to those in steadystate patients and in controls, without any reported toxicity. However, in a phase II, randomized, placebo-controlled trial of 92 SCD patients, a 48-hour infusion of regadenoson at the same dose during VOC did not significantly decrease iNKT-cell activation or the severity of the crises. $^{75}$

Another approach based on iNKT-specific depletion with the humanized $\operatorname{IgG} 1 \kappa$ monoclonal antibody NKTT120 is currently under investigation, and it has already been shown that a single intravenous bolus produces rapid, specific and sustained iNKT-cell depletion, thereby allowing for a regimen of infusion every 3 months. ${ }^{76}$ Because iNKT cells play important roles in immunity, there are legitimate concerns about a possible increase in susceptibility to infections, but no adverse effect was reported in a first multicenter, single-ascendingdose trial designed to determine the pharmacokinetics, pharmacodynamics and safety in SCD patients in steadystate. The next step should be a randomized, doubleblind, placebo-controlled trial to assess the efficacy of NKTT120 in preventing VOC occurrence.

\section{Platelets}

Platelets are essential in hemostasis and thrombosis, but they are also important mediators of vascular inflammation. Platelets were found to be activated in SCD patients in steady-state and even more so during VOC., 87 Platelet

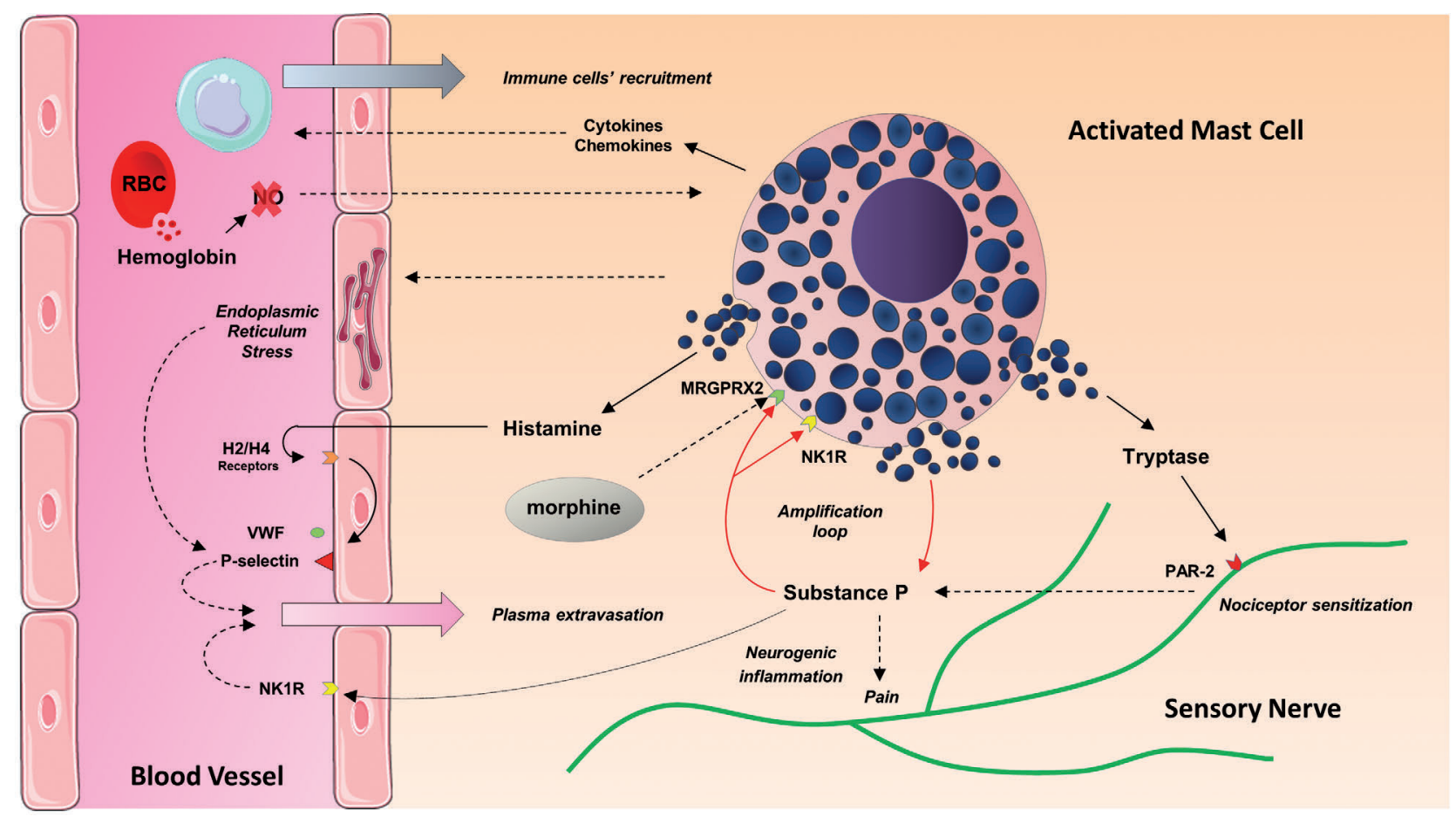

Figure 3. Mast cells in sickle cell disease. Histamine released from mast cells (MC) stimulates endothelial $\mathrm{H}_{2}$ and $\mathrm{H}_{4}$ receptors, thereby inducing the release of von Willebrand factor and expression of P-selectin. Tryptase released from MC activates protease-activated receptor 2 on peripheral nerve endings, thus contributing to nociceptor sensitization and stimulating the release of substance P (SP). SP released from MC and from sensory nerve endings increases plasma extravasation via neurokinin 1 receptor (NK1R) and promotes neurogenic inflammation. SP also acts on MC via NK1R and MAS-related G-protein-coupled receptor X2 (MRGPRX2), thus inducing more SP release in an amplification loop of MC activation. MRGPRX2 stimulation by SP induces the release of several cytokines and chemokines, which promotes immune cell recruitment. MC degranulation in response to morphine is also mediated by MRGPRX2. Hemolysis in sickle cell disease (SCD) may contribute to $\mathrm{MC}$ activation because it is responsible for nitric oxide depletion, which is known to activate MC. MC activation appears to contribute to endothelial dysfunction in SCD, via endoplasmic reticulum stress-mediated P-selectin expression and increased endothelial permeability. NO: nitric oxide; PAR-2: protease-activated receptor 2; RBC: red blood cell; VWF: von Willebrand factor. 
Table 1. The main potential therapeutic agents targeting innate immune cells in sickle cell disease.

\begin{tabular}{|c|c|c|c|c|}
\hline Therapeutic agent & Targeted innate immune cells & Mechanism of action & Study ID \# & Phase \\
\hline Hydroxyurea & $\begin{array}{l}\text { Neutrophils, eosinophils, } \\
\text { monocytes, NK cells, platelets }\end{array}$ & $\begin{array}{l}\text { Multimodal mechanism including } \\
\text { myelosuppression }\end{array}$ & FDA-approved & III \\
\hline Crizanlizumab (SEG101) & Neutrophils, platelets & $\begin{array}{l}\text { P-selectin inhibitor } \\
\text { (monoclonal antibody) }\end{array}$ & $\begin{array}{l}\text { NCT03814746 } \\
\text { FDA-approved }\end{array}$ & III \\
\hline Rivipansel (GMI-1070) & Neutrophils, platelets & Pan-selectin inhibitor & NCT02187003 & III \\
\hline Sevuparin & Neutrophils, platelets & $\begin{array}{l}\text { Multimodal mechanism including } \\
\text { P- and L-selectin inhibition }\end{array}$ & NCT02515838 & II \\
\hline IVIG & Neutrophils & $\begin{array}{l}\text { Inhibits neutrophil adhesion } \\
\text { and RBC-neutrophil interactions }\end{array}$ & NCT01757418 & II \\
\hline NKTT120 & iNKT cells & $\begin{array}{l}\text { iNKT cell depletion } \\
\text { (monoclonal antibody) }\end{array}$ & NCT01783691 & I \\
\hline Ticagrelor & Platelets & ADP receptor antagonist & NCT03615924 & III \\
\hline
\end{tabular}

ID \#: identification number; NK cells: natural killer cells; FDA: US Food and Drug Administration; IVIG: intravenous immunoglobulin; RBC: red blood cell; iNKT cells: invariant natural killer T cells; ADP: adenosine diphosphate.

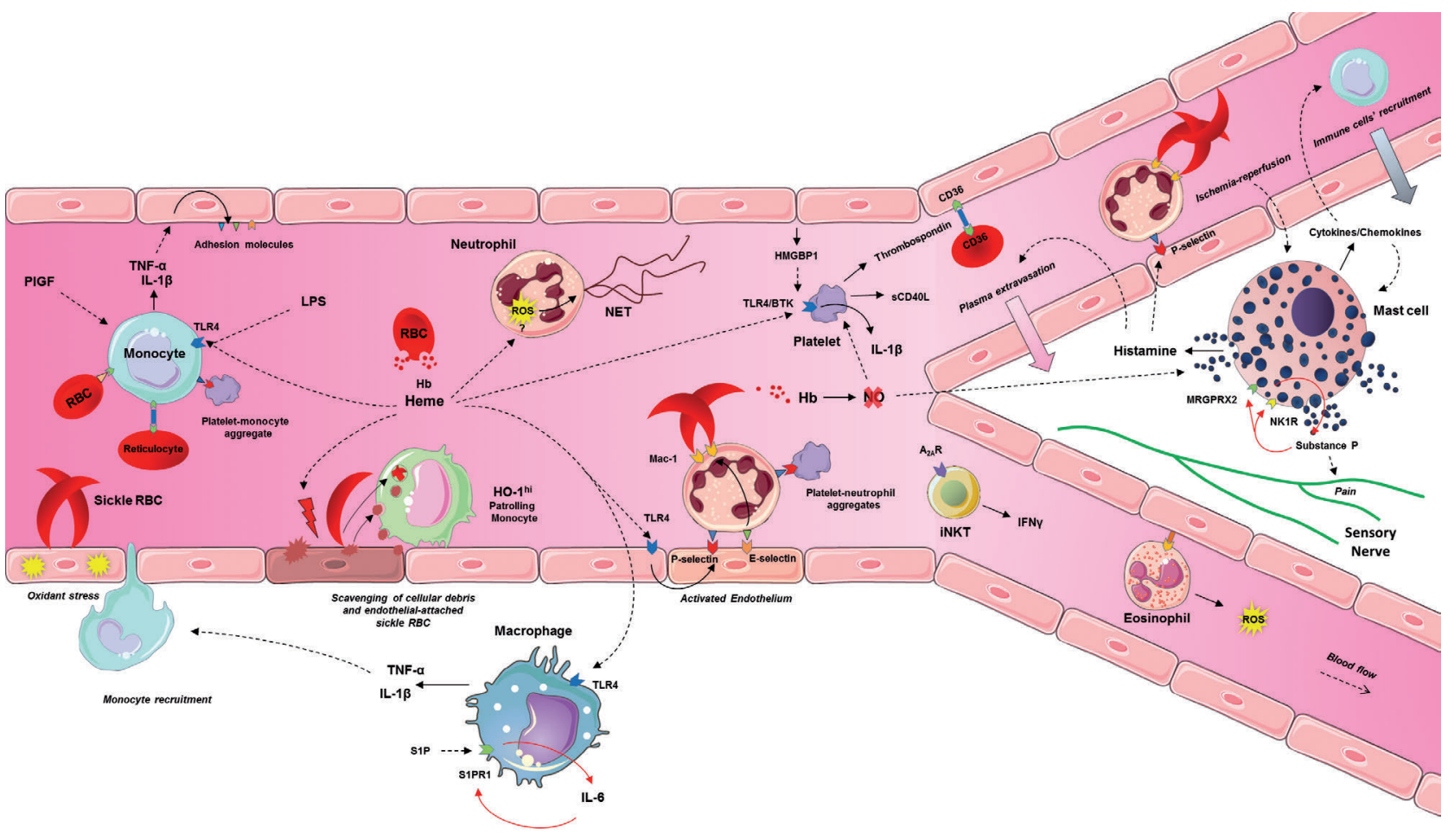

Figure 4. Main roles of innate immune cells in sickle cell disease. Innate immune cells promote inflammation, adhesion and pain in sickle cell disease (SCD) Monocytes may be activated by several mechanisms, including interactions with red blood cells (RBC), reticulocytes and platelets, as well as toll-like receptor 4 (TLR4) stimulation by heme and lipopolysaccharide. Activated monocytes produce pro-inflammatory cytokines, such as interleukin (IL)-1 $\beta$ and tumor necrosis factor- $\alpha$, which activate endothelial cells, resulting in enhanced expression of adhesion molecules. The interaction of sickle RBC with endothelial cells induces cellular oxidant stress, which leads to transendothelial migration of blood monocytes. Patrolling monocytes scavenge endothelium-adherent sickle RBC and take up cellular debris derived from heme-exposed endothelial cells, thereby leading to high expression of heme oxygenase-1. Macrophages may be activated by heme, released from RBC in SCD, resulting in increased production of pro-inflammatory cytokines, especially IL-1 $\beta$, through activation of the NLRP3 inflammasome. Elevated plasma levels of sphingosine-1-phosphate (S1P) induce IL-6 expression via S1P receptor 1 (S1PR1), and IL-6 in turn promotes S1PR1 expression by macrophages, leading to a vicious cycle of chronic inflammation. Neutrophil adhesion involves endothelial P-selectin, which is upregulated in response to TLR4 activation by heme in SCD. Heme may also promote neutrophil extracellular trap formation via the generation of reactive oxygen species (ROS) in neutrophils. Endothelial E-selectin induces the clustering of macrophage-1 antigen (Mac-1) on the leading edge of adherent neutrophils, allowing for the capture of sickle RBC. P-selectin is also expressed by platelets, which promotes the formation of platelet-neutrophil aggregates. The platelet NLRP3 inflammasome is activated in SCD, via HMGB1/TLR4 and Bruton tyrosine kinase, leading to enhanced production of pro-inflammatory cytokines, including IL-1 $\beta$. Increased platelet activation may also result from depletion of nitric oxide (NO), secondary to the release of free hemoglobin from RBC. Activated platelets release soluble CD4OL and thrombospondin, which binds CD36 on both endothelial cells and RBC, thereby promoting RBC adhesion to microvascular endothelium. Mast cell activation in SCD may be mediated by ischemia-reperfusion, hemolysis with NO depletion, and chronic inflammation. Substance P released from mast cells promotes neurogenic inflammation and pain, but it also activates mast cells themselves via neurokinin 1 receptor and MAS-related G-protein-coupled receptor X2, thereby inducing a vicious cycle of substance P release as well as the release of pro-inflammatory cytokines and chemokines, which promotes immune cell recruitment. Histamine released from mast cells also induces plasma extravasation and endothelial $\mathrm{P}$ selectin expression. Invariant natural killer T-cell activation in SCD is associated with increased interferon-y production and $A_{2 A}$ receptor expression. Adhesion of circulating eosinophils to fibronectin in SCD is mediated by several integrins, including Mac-1, and activated eosinophils are responsible for enhanced ROS production. $A_{2 A} R$ : adenosine $A_{2 A}$ receptor; BTK: Bruton tyrosine kinase; Hb: hemoglobin; HO-1: heme oxygenase-1; IFN: interferon; iNKT cell: invariant natural killer T cell; LPS: lipopolysaccharide; MRGPRX2: MAS-related G-protein-coupled receptor X2; NET: neutrophil extracellular traps; NK1R: neurokinin 1 receptor; PIGF: placental growth factor; TLR: toll-like receptor 4; TNF- $\alpha$ : tumor necrosis factor alpha. 
activation was positively correlated with pulmonary arterial hypertension, and activated platelets might contribute to this severe complication of SCD by promoting in situ thrombosis and releasing vasoactive molecules or mitogenic mediators. ${ }^{77}$ Recently, elevated plasma levels of soluble CD40L and thrombospondin-1, two platelet-derived molecules, were reported in SCD patients with a history of ACS, which suggests a role for activated platelets in the pathogenesis of this syndrome. ${ }^{78}$ In support of this hypothesis, antiplatelet agents such as the ADP receptor antagonist clopidogrel significantly improved lung injury in SCD mice. ${ }^{51}$ As described above, activated platelets can form aggregates with several cells, including RBC, monocytes and neutrophils, and platelet-neutrophil aggregates may contribute to pulmonary arteriole microemboli in SCD mice. ${ }^{52}$ By releasing thrombospondin, which binds CD36 on both endothelial cells and RBC, platelets also promote sickle RBC adhesion to microvascular endothelium, resulting in vaso-occlusion. ${ }^{79}$ These findings have supported clinical trials of two antiplatelet agents in SCD patients, namely the ADP receptor antagonists prasugrel and ticagrelor. However, a phase III trial of prasugrel in SCD children did not find a significant reduction of VOC rate, and ticagrelor did not affect diary-reported pain in a phase IIb trial of young adults with SCD. ${ }^{80,81}$ A ticagrelor phase III trial on VOC rate in children with SCD is currently ongoing (\#NCT03615924).

Increased platelet activation in SCD may result from decreased nitric oxide bioavailability and endothelial dysfunction with an abnormal prothrombotic microvasculature. ${ }^{77}$ However, new insights into mechanisms of platelet activation in SCD were provided by the recent demonstration that the platelet NLRP3 inflammasome is activated in SCD patients in steady-state, and even more during VOC, via HMGB1/TLR4 and Bruton tyrosine kinase (BTK). ${ }^{82}$ The NLRP3 inflammasome mediates platelet activation/aggregation and thrombus formation via recognition of various pathogen-associated molecular patterns (PAMP) and damage-associated molecular patterns (DAMP) from injured tissues, such as HMGB1, whose level was found to be higher in plasma from SCD patients than in plasma from healthy controls. ${ }^{82}$ The platelet NLRP3 inflammasome is involved in IL-1 $\beta$ signaling and platelets from SCD patients were found to produce increased amounts of pro-inflammatory cytokines, including IL-1 $\beta .^{83}$ In vitro, pharmacological or antibody-mediated inhibition of HMGB1/TLR4 and BTK decreased the ability of SCD patients' plasma to induce caspase-1 activation in platelets from healthy controls. Similarly, in sickle mice, inhibition of NLRP3 or BTK reduced caspase-1 activity and platelet aggregation. ${ }^{82}$ These findings may open therapeutic perspectives in SCD, especially for the BTK inhibitor ibrutinib, which is approved by the US Food and Drug Administration to treat B-cell malignancies.

\section{Macrophages}

A polarization of liver macrophages into a M1 proinflammatory phenotype was recently described in SCD mice, with higher expression of TNF- $\alpha$ and IL- 6 by these cells than by liver macrophages from control mice. ${ }^{84}$ This could contribute to the pathogenesis of SCD liver damage because pro-inflammatory activation of liver macrophages is known to induce monocyte recruitment, with enhanced cytokine production leading to hepatocyte apoptosis and fibrosis. Additionally, administration of hemopexin to SCD mice attenuated the pro-inflammatory status of liver macrophages, which strongly suggests a role for heme in inducing the SCD macrophage phenotypic switch toward an M1 phenotype. ${ }^{84}$ Macrophages may also be a major source of IL- $1 \beta$ in SCD because heme induces IL-1 $\beta$ processing through NLRP3 inflammasome activation in macrophages. ${ }^{85}$

Infiltration of macrophages has been described in kidneys of SCD mice, with macrophage stimulating protein 1 (MSP1) accumulation in glomerular capillaries. ${ }^{86} \mathrm{MSP} 1$ activates $\mathrm{RON}$ kinase on glomerular endothelial cells, leading to the phosphorylation of ERK and AKT and resulting in increased von Willebrand factor expression, cell motility and glomeruli permeability. Treating SCD mice with a RON inhibitor (BMS-777607) attenuated glomerular endothelial injury, which suggests that this molecule could be used to prevent renal disease in SCD patients. ${ }^{86}$

Another interesting finding concerns sphingosine-1phosphate (S1P), a biolipid contributing to chronic inflammation, whose plasma levels are elevated in SCD patients and mice. In SCD mice, S1P induces IL-6 expression in macrophages via S1P receptor 1 (S1PR1) and IL-6 in turn promotes S1PR1 expression in macrophages of several organs, which leads to a vicious cycle promoting chronic inflammation and tissue damage. ${ }^{87}$ Treating SCD mice with a S1PR1 antagonist (FTY720) reduced systemic inflammation and improved tissue damage in the spleen, liver, kidneys and lungs, which suggests that this drug, approved by the US Food and Drug Administration to treat multiple sclerosis as an immunosuppressant, may benefit SCD patients. ${ }^{87}$

\section{Mast cells}

Growing evidence is suggesting a role for mast cells in the pathophysiology of SCD. The chronic pain in this disease shares many characteristics with that encountered in mastocytosis, and the clinical signs of mast cell activation syndrome have been described in SCD patients. ${ }^{88}$ Increased plasma levels of several mast cell mediators, including histamine and substance $\mathrm{P}$, have been reported in steady-state with further enhancement during VOC. ${ }^{89,90}$ The plasma tryptase level is also slightly increased during VOC as compared with the level in steady-state but without reaching pathological values, which suggests mast-cell activation rather than increased numbers of mast cells. ${ }^{89}$ In SCD patients, plasma histamine level was found to be negatively correlated with $\mathrm{HbF}$ level, a well-known protective factor in SCD, and positively with absolute neutrophil count, absolute platelet count and C-reactive protein level, which suggests a role for inflammation in the mechanisms leading to mast-cell activation. ${ }^{89}$ Histamine may contribute to SCD pathogenesis, because stimulation of endothelial histamine $\mathrm{H}_{2}$ and $\mathrm{H}_{4}$ receptors induced the release of von Willebrand factor and P-selectin expression by endothelial cells, thus promoting adhesion of sickle RBC. ${ }^{91}$ Furthermore, the plasma level of substance $P$ was found to be negatively correlated with hemoglobin concentration and positively with the levels of markers of hemolysis..$^{90}$ These findings may reflect SCD hemolysis being responsible for depletion of nitric oxide, which is known to induce mast-cell activation. ${ }^{92}$

Substance P, a neuropeptide released from mast cells and from sensory nerve endings, acts as a primary pain neurotransmitter and a neuromodulator. Via neurokinin 1 receptor (NK1R), substance $P$ contributes to neurogenic inflammation by increasing venular permeability and plas- 
ma extravasation, but it also acts on the mast cells themselves, promoting a vicious cycle of mast-cell activation and substance $\mathrm{P}$ release. ${ }^{93}$ Furthermore, tryptase released from mast cells activates protease-activated receptor 2 (PAR-2) on peripheral nerve endings, thus contributing to nociceptor sensitization and stimulating the release of substance $\mathrm{P}$, which in turn activates mast cells. ${ }^{94}$ Substance $\mathrm{P}$ and tryptase levels were higher in the skin of SCD mice than in that of control mice and both proteins colocalized with activated mast cells. ${ }^{93,95}$ Inhibition of mast cells, with the mast-cell stabilizer cromolyn or the c-kit/tyrosine kinase inhibitor imatinib, decreased substance $\mathrm{P}$ and tryptase levels as well as systemic inflammation, neurogenic inflammation, reflected by Evans blue leakage, and hyperalgesia. Importantly, these results were confirmed in transgenic SCD mice lacking mast cells. ${ }^{93}$ In the same line of evidence, in an SCD patient with chronic myeloid leukemia, imatinib treatment completely resolved repeated VOC, and discontinuation of the treatment coincided with VOC recurrence. ${ }^{96}$ However, this may be explained, at least in part, by a decrease in leukocyte and neutrophil counts during imatinib treatment, and further studies are needed. A clinical trial of imatinib or another c-kit/tyrosine kinase inhibitor in SCD patients may be considered.

Treating SCD mice with a high-affinity opioid nociception receptor agonist, AT-200, known to inhibit the release of substance $\mathrm{P}$ from sensory nerve endings, inhibited mastcell activation/degranulation as well as neurogenic inflammation, with a greater antinociceptive effect than that of morphine. ${ }^{97}$ In SCD mice, morphine was found to stimulate the release of substance $P$ from mast cells, thereby promoting neurogenic inflammation and hyperalgesia mediated by mast-cell activation..$^{93}$ In SCD patients, morphine is considered a reference analgesic for VOC but it may actually have deleterious effects by inducing the release of mast-cell mediators, including substance $\mathrm{P}$ and histamine. ${ }^{89}$ Importantly, human mast-cell degranulation in response to morphine was recently found to be mediated by MAS-related G-protein-coupled receptor X2 (MRGPRX2), which is also a major receptor for substance $\mathrm{P}$, mediating innate immune cell recruitment, neurogenic inflammation, and pain..$^{98,99}$

Mast-cell activation may have an additional role in promoting blood-brain barrier dysfunction in SCD. In vitro, activated mast cells from SCD mice induced endoplasmic reticulum stress in brain endothelial cells, with increased P-selectin expression and increased endothelial permeability. ${ }^{100}$ Hence, mast-cell activation may contribute to endothelial dysfunction in SCD via endoplasmic reticulum stress-mediated P-selectin expression.

The main findings on the involvement of mast cells in SCD pathophysiology are summarized in Figure 3.
The main potential therapeutic agents targeting innate immune cells in SCD are described in Table 1.

\section{Conclusion}

Findings from our review suggest that innate immune cells do indeed play important roles in SCD in promoting inflammation, adhesion and pain, the hallmarks of the disease (Figure 4).

Among suspected mechanisms underlying innate immune cell activation, free hemoglobin and heme released by hemolysis may play a crucial role by activating TLR4 or generating ROS that can activate the inflammasome. ${ }^{85}$ Nitric oxide depletion by free hemoglobin may also contribute, especially to platelet and mast-cell activation. Innate immune cells usually possess a large repertoire of receptors, including cytokine and chemokine receptors, which enables them to respond to various inflammatory signals. Hence, their activation in SCD is likely promoted by chronic and acute inflammation. SCD patients have increased susceptibility to infections, and PAMP, such as bacterial lipopolysaccharides or endotoxins, could also contribute, as could DAMP originating from injured tissues following ischemia/reperfusion.

Once activated, innate immune cells release a wide range of cytokines and chemokines, thus promoting a vicious cycle of immune cell recruitment and activation. Pro-inflammatory cytokines produced mainly by monocytes and macrophages, but also by platelets and other innate immune cells, can activate the endothelium together with heme, resulting in increased expression of adhesion molecules. Neutrophils are crucial factors in endothelial adhesion but monocytes and platelets also contribute to decreased blood flow and vaso-occlusion via the formation of RBC-monocyte, platelet-monocyte and plateletneutrophil aggregates. However, activated innate immune cells are not just deleterious protagonists in SCD, as illustrated by patrolling monocytes, which scavenge endothelial debris and adherent sickle RBC.

Innate immune cells may play a specific role in SCD. For example, mast cells promote neurogenic inflammation via substance $\mathrm{P}$ release. However, the main complications of SCD, such as VOC, ACS and stroke, likely result from interlinked actions of innate immune cells. Further investigations are required to better understand the involvement of these novel, important protagonists in SCD pathophysiology, their respective roles in acute and chronic complications, as well as the mechanisms underlying their activation, in order to develop innovative treatments targeting innate immune cells in SCD.

\section{References}

1. Ware RE, de Montalembert M, Tshilolo L, Abboud MR. Sickle cell disease. Lancet. 2017;390(10091):311-323.

2. Piel FB, Steinberg MH, Rees DC. Sickle cell disease. N Engl J Med. 2017;376(16):15611573.

3. Wongtong N, Jones S, Deng Y, Cai J, Ataga $\mathrm{KI}$. Monocytosis is associated with hemoly- sis in sickle cell disease. Hematology 2015;20(10):593-597.

4. Nickel RS, Osunkwo I, Garrett A, et al. Immune parameter analysis of children with sickle cell disease on hydroxycarbamide or chronic transfusion therapy. Br J Haematol. 2015;169(4):574-583.

5. Sultana C, Shen Y, Rattan V, Johnson C, Kalra VK. Interaction of sickle erythrocytes with endothelial cells in the presence of endothelial cell conditioned medium induces oxidant stress leading to transendothelial migration of monocytes. Blood. 1998;92(10):3924-3935

6. Belcher JD, Marker PH, Weber JP, Hebbel RP, Vercellotti GM. Activated monocytes in sickle cell disease: potential role in the activation of vascular endothelium and vasoocclusion. Blood. 2000;96(7):2451-2459.

7. Wun T, Cordoba M, Rangaswami A Cheung AW, Paglieroni T. Activated monocytes and platelet-monocyte aggregates in 
patients with sickle cell disease. Clin Lab Haematol. 2002;24(2):81-88.

8. Inwald DP, Kirkham FJ, Peters MJ, et al. Platelet and leucocyte activation in childhood sickle cell disease: association with nocturnal hypoxaemia. Br J Haematol. 2000;111(2):474-481.

9. Sloma I, Zilber MT, Charron D, Girot R, Tamouza R, Gelin C. Upregulation and atypical expression of the $\mathrm{CD} 1$ molecules on monocytes in sickle cell disease. Hum Immunol. 2004;65(11):1370-1376.

10. Dias-Da-Motta P, Arruda VR, Muscara MN, et al. The release of nitric oxide and superoxide anion by neutrophils and mononuclear cells from patients with sickle cell anaemia. Br J Haematol. 1996;93(2):333-340.

11. Marcal LE, Dias-da-Motta PM, Rehder J, et al. Up-regulation of NADPH oxidase components and increased production of interferongamma by leukocytes from sickle cell disease patients. Am J Hematol. 2008;83(1): 41-45.

12. Setty BN, Key NS, Rao AK, et al. Tissue factor-positive monocytes in children with sickle cell disease: correlation with biomarkers of haemolysis. Br J Haematol. 2012;157(3):370-380.

13. Ragab SM, Soliman MA. Tissue factor-positive monocytes expression in children with sickle cell disease: clinical implication and relation to inflammatory and coagulation markers. Blood Coagul Fibrinolysis. 2016;27(8):862-869

14. Solovey A, Somani A, Belcher JD, et al. A monocyte-TNF-endothelial activation axis in sickle transgenic mice: therapeutic benefit from TNF blockade. Am J Hematol. 2017;92(11):1119-1130

15. Brittain JE, Knoll CM, Ataga KI, Orringer EP, Parise LV. Fibronectin bridges monocytes and reticulocytes via integrin alpha4beta1. Br J Haematol. 2008;141(6):872-881.

16. Selvaraj SK, Giri RK, Perelman N, Johnson C, Malik P, Kalra VK. Mechanism of monocyte activation and expression of proinflammatory cytochemokines by placenta growth factor. Blood. 2003;102(4):1515-1524.

17. Perelman N, Selvaraj SK, Batra S, et al. Placenta growth factor activates monocytes and correlates with sickle cell disease severity. Blood. 2003;102(4):1506-1514.

18. Sundaram N, Tailor A, Mendelsohn L, et al. High levels of placenta growth factor in sickle cell disease promote pulmonary hypertension. Blood. 2010;116(1):109-112.

19. Zennadi R, Chien A, Xu K, Batchvarova M, Telen MJ. Sickle red cells induce adhesion of lymphocytes and monocytes to endothelium. Blood. 2008;112(8):3474-3483.

20. Chaar V, Picot J, Renaud O, et al. Aggregation of mononuclear and red blood cells through an \{alpha\}4\{beta\}1-Lu/basal cell adhesion molecule interaction in sickle cell disease. Haematologica. 2010:95(11):1841-1848.

21. Dagur PK, McCoy JP, Nichols J, et al. Haem augments and iron chelation decreases tolllike receptor 4 mediated inflammation in monocytes from sickle cell patients. Br J Haematol. 2018;181(4):552-554.

22. Liu Y, Jing F, Yi W, et al. HO-1(hi) patrolling monocytes protect against vaso-occlusion in sickle cell disease. Blood. 2018;131(14):16001610.

23. Liu Y, Zhong H, Bao W, et al. Patrolling monocytes scavenge endothelial adherent sickle RBC: a novel mechanism of inhibition of vaso-occlusion in SCD. Blood. 2019;134(7):579-590.

24. Yazdanbakhsh K, Ware RE, Noizat-Pirenne F. Red blood cell alloimmunization in sickle cell disease: pathophysiology, risk factors, and transfusion management. Blood.
2012;120(3):528-537

25. Godefroy E, Liu Y, Shi P, et al. Altered hememediated modulation of dendritic cell function in sickle cell alloimmunization Haematologica. 2016;101(9):1028-1038.

26. Abhishek K, Kumar R, Arif E, Patra PK, Choudhary SB, Sohail M. Induced expression of bone morphogenetic protein- 6 and Smads signaling in human monocytes derived dendritic cells during sickle-cell pathology with orthopedic complications. Biochem Biophys Res Commun. 2010;396(4):950-955.

27. Anyaegbu CC, Okpala IE, Akren'Ova YA, Salimonu LS. Peripheral blood neutrophil count and candidacidal activity correlate with the clinical severity of sickle cell anaemia (SCA). Eur J Haematol. 1998;60(4): 267-268.

28. Platt OS, Brambilla DJ, Rosse WF, et al. Mortality in sickle cell disease. Life expectancy and risk factors for early death N Engl J Med. 1994;330(23):1639-1644.

29. Castro O, Brambilla DJ, Thorington B, et al. The acute chest syndrome in sickle cell disease: incidence and risk factors. The Cooperative Study of Sickle Cell Disease. Blood. 1994:84(2):643-649.

30. Ohene-Frempong K, Weiner SJ, Sleeper LA et al. Cerebrovascular accidents in sickle cell disease: rates and risk factors. Blood. 1998;91(1):288-294

31. Wigfall DR, Ware RE, Burchinal MR, Kinney TR, Foreman JW. Prevalence and clinical correlates of glomerulopathy in children with sickle cell disease. J Pediatr. 2000;136(6):749753

32. Wali Y, Beshlawi I, Fawaz N, et al. Coexistence of sickle cell disease and severe congenital neutropenia: first impressions can be deceiving. Eur J Haematol. 2012;89(3): 245-249.

33. Adler BK, Salzman DE, Carabasi MH, Vaughan WP, Reddy VV, Prchal JT. Fatal sickle cell crisis after granulocyte colony-stimulating factor administration. Blood. 2001;97(10):3313-3314

34. Pieters RC, Rojer RA, Saleh AW, Saleh AE, Duits AJ. Molgramostim to treat SS-sickle cell leg ulcers. Lancet. 1995;345(8948):528.

35. Charache S. Mechanism of action of hydroxyurea in the management of sickle cell anemia in adults. Semin Hematol. 1997;34(3 Suppl 3):15-21

36. Fadlon E, Vordermeier S, Pearson TC, et al Blood polymorphonuclear leukocytes from the majority of sickle cell patients in the crisis phase of the disease show enhanced adhesion to vascular endothelium and increased expression of CD64. Blood. 1998;91(1):266-274

37. Lum AF, Wun T, Staunton D, Simon SI. Inflammatory potential of neutrophils detected in sickle cell disease. Am J Hematol. 2004;76(2):126-133

38. Okpala I, Daniel Y, Haynes R, Odoemene D, Goldman J. Relationship between the clinical manifestations of sickle cell disease and the expression of adhesion molecules on white blood cells. Eur J Haematol. 2002;69(3):135-144

39. Benkerrou M, Delarche C, Brahimi L, et al. Hydroxyurea corrects the dysregulated Lselectin expression and increased $\mathrm{H}(2) \mathrm{O}(2)$ production of polymorphonuclear neutrophils from patients with sickle cell anemia. Blood. 2002;99(7):2297-2303

40. Almeida CB, Scheiermann C, Jang JE, et al. Hydroxyurea and a cGMP-amplifying agent have immediate benefits on acute vasoocclusive events in sickle cell disease mice. Blood. 2012;120(14):2879-2888
41. Turhan A, Weiss LA, Mohandas N, Coller BS, Frenette PS. Primary role for adherent leukocytes in sickle cell vascular occlusion: a new paradigm. Proc Natl Acad Sci U S A. 2002;99(5):3047-3051

42. Hidalgo A, Chang J, Jang JE, Peired AJ, Chiang EY, Frenette PS. Heterotypic interactions enabled by polarized neutrophil microdomains mediate thromboinflammatory injury. Nat Med. 2009;15(4):384-391.

43. Zhang D, Xu C, Manwani D, Frenette PS Neutrophils, platelets, and inflammatory pathways at the nexus of sickle cell disease pathophysiology. Blood. 2016;127(7):801809

44. Morikis VA, Chase S, Wun T, Chaikof EL Magnani JL, Simon SI. Selectin catch-bonds mechanotransduce integrin activation and neutrophil arrest on inflamed endothelium under shear flow. Blood. 2017;130(19):2101 2110.

45. Chang I, Patton IT, Sarkar A, Ernst B, Magnani JL, Frenette PS. GMI-1070, a novel pan-selectin antagonist, reverses acute vascular occlusions in sickle cell mice. Blood. 2010;116(10):1779-1786

46. Telen MJ, Wun T, McCavit TL, et al Randomized phase 2 study of GMI-1070 in SCD: reduction in time to resolution of vaso-occlusive events and decreased opioid use. Blood. 2015;125(17):2656-2664

47. Ataga KI, Kutlar A, Kanter J, et al Crizanlizumab for the prevention of pain crises in sickle cell disease. N Engl J Med. 2017;376(5):429-439.

48. Telen MJ, Batchvarova M, Shan S, et al Sevuparin binds to multiple adhesive ligands and reduces sickle red blood cell-induced vaso-occlusion. Br J Haematol. 2016;175(5): 935-948.

49. White J, Lindgren M, Liu K, Gao X, Jendeberg L, Hines P. Sevuparin blocks sickle blood cell adhesion and sickle-leucocyte rolling on immobilized L-selectin in a dose dependent manner. Br J Haematol. 2019;184 (5):873-876.

50. Manwani D, Chen G, Carullo V, et al Single-dose intravenous gammaglobulin can stabilize neutrophil Mac-1 activation in sickle cell pain crisis. Am J Hematol. 2015, 90(5):381-385

51. Polanowska-Grabowska R, Wallace K, Field JJ, et al. P-selectin-mediated platelet-neutrophil aggregate formation activates neutrophils in mouse and human sickle cell disease. Arterioscler Thromb Vasc Biol. 2010;30(12):2392-2399.

52. Bennewitz MF, Jimenez MA, Vats $R$, et al Lung vaso-occlusion in sickle cell disease mediated by arteriolar neutrophil-platelet microemboli. JCI Insight. 2017;2(1):e89761.

53. Li J, Kim K, Hahm E, et al. Neutrophil AKT2 regulates heterotypic cell-cell interactions during vascular inflammation. J Clin Invest. 2014;124(4):1483-1496.

54. Kim K, Li J, Barazia A, et al. ARQ 092, an orally-available, selective AKT inhibitor, attenuates neutrophil-platelet interactions in sickle cell disease. Haematologica. 2017;102(2):246-259.

55. Jimenez MA, Novelli E, Shaw GD, Sundd P. Glycoprotein Ibalpha inhibitor (CCP-224) prevents neutrophil-platelet aggregation in Sickle Cell Disease. Blood Adv. 2017;1(20): 1712-1716

56. Koehl B, Nivoit P, El Nemer W, et al. The endothelin B receptor plays a crucial role in the adhesion of neutrophils to the endothelium in sickle cell disease. Haematologica. 2017;102(7):1161-1172.

57. Zhang D, Chen G, Manwani D, et al. Neutrophil ageing is regulated by the micro- 
biome Nature 2015.525(7570):528-532.

58. Rana K, Pantoja K, Xiao L. Bone marrow neutrophil aging in sickle cell disease mice is associated with impaired osteoblast functions. Biochem Biophys Rep. 2018;16:110114.

59. Chen G, Zhang D, Fuchs TA, Manwani D, Wagner DD, Frenette PS. Heme-induced neutrophil extracellular traps contribute to the pathogenesis of sickle cell disease. Blood. 2014;123(24):3818-3827.

60. Ghosh S, Adisa OA, Chappa P, et al. Extracellular hemin crisis triggers acute chest syndrome in sickle mice. J Clin Invest. 2013;123(11):4809-4820.

61. Evans C, Orf K, Horvath E, et al. Impairment of neutrophil oxidative burst in children with sickle cell disease is associated with heme oxygenase-1. Haematologica. 2015;100(12):1508-1516.

62. Canalli AA, Conran N, Fattori A, Saad ST, Costa FF. Increased adhesive properties of eosinophils in sickle cell disease. Exp Hematol. 2004:32(8):728-734

63. Pallis FR, Conran N, Fertrin KY, Olalla Saad ST, Costa FF, Franco-Penteado CF. Hydroxycarbamide reduces eosinophil adhesion and degranulation in sickle cell anaemia patients. Br J Haematol. 2014;164 (2):286-295.

64. Conran N, Saad ST, Costa FF, Ikuta T. Leukocyte numbers correlate with plasma levels of granulocyte-macrophage colonystimulating factor in sickle cell disease. Ann Hematol. 2007;86(4):255-261

65. Qari MH, Zaki WA. Flow cytometric assessment of leukocyte function in sickle cell anemia. Hemoglobin. 2011;35(4):367-381.

66. Abraham AA, Lang $\mathrm{H}$, Meier ER, et al Characterization of natural killer cells expressing markers associated with maturity and cytotoxicity in children and young adults with sickle cell disease. Pediatr Blood Cancer. 2019;66(5):e27601.

67. Al Najiar S, Adam S, Ahmed N, Oari M. Markers of endothelial dysfunction and leucocyte activation in Saudi and non-Saudi haplotypes of sickle cell disease. Ann Hematol. 2017;96(1):141-146.

68. Dedeken L, Le PQ, Azzi N, et al. Haematopoietic stem cell transplantation for severe sickle cell disease in childhood: a single centre experience of 50 patients. $\mathrm{Br} \mathrm{J}$ Haematol. 2014;165(3):402-408.

69. Wallace KL, Linden J. Adenosine A2A receptors induced on iNKT and NK cells reduce pulmonary inflammation and injury in mice with sickle cell disease. Blood. 2010;116(23):5010-5020.

70. Lappas CM, Day YJ, Marshall MA, Engelhard VH, Linden J. Adenosine A2A receptor activation reduces hepatic ischemia reperfusion injury by inhibiting CD1ddependent NKT cell activation. J Exp Med. 2006;203(12):2639-2648.

71. Wallace KL, Marshall MA, Ramos SI, et al. NKT cells mediate pulmonary inflammation and dysfunction in murine sickle cell disease through production of IFN-gamma and CXCR3 chemokines. Blood. 2009;114
(3):667-676

72. Lin G, Field JJ, Yu JC, et al. NF-kappaB is activated in CD4+ iNKT cells by sickle cell disease and mediates rapid induction of adenosine A2A receptors. PLoS One. 2013;8 (10):e74664.

73. Yu JC, Lin G, Field JJ, Linden J. Induction of antiinflammatory purinergic signaling in activated human iNKT cells. JCI Insight. 2018;3(17)

74. Field JJ, Lin G, Okam MM, et al. Sickle cell vaso-occlusion causes activation of iNKT cells that is decreased by the adenosine $\mathrm{A} 2 \mathrm{~A}$ receptor agonist regadenoson. Blood. 2013;121(17):3329-3334.

75. Field JJ, Majerus E, Gordeuk VR, et al Randomized phase 2 trial of regadenoson for treatment of acute vaso-occlusive crise in sickle cell disease Blood Adv. 2017;1(20):1645-1649

76. Field JJ, Majerus E, Ataga KI, et al. NNKTT120, an anti-iNKT cell monoclonal antibody, produces rapid and sustained iNKT cell depletion in adults with sickle cell disease. PLoS One. 2017;12(2):e0171067.

77. Villagra J, Shiva S, Hunter LA, Machado RF, Gladwin MT, Kato GJ. Platelet activation in patients with sickle disease, hemolysis-associated pulmonary hypertension, and nitric oxide scavenging by cell-free hemoglobin. Blood. 2007:110(6):2166-2172.

78. Garrido VT, Sonzogni L, Mtatiro SN, Costa FF, Conran N, Thein SL. Association of plasma CD40L with acute chest syndrome in sickle cell anemia. Cytokine. 2017;97:104107.

79. Brittain HA, Eckman JR, Swerlick RA, Howard RJ, Wick TM. Thrombospondin from activated platelets promotes sickle erythrocyte adherence to human microvascular endothelium under physiologic flow: a potential role for platelet activation in sickle cell vaso-occlusion. Blood. 1993;81(8):21372143

80. Heeney MM, Hoppe CC, Abboud MR, et al. A multinational trial of prasugrel for sickle cell vaso-occlusive events. N Engl J Med. 2016;374(7):625-635

81. Kanter J, Abboud MR, Kaya B, et al. Ticagrelor does not impact patient-reported pain in young adults with sickle cell disease: multicentre, randomised phase IIb study. Br J Haematol. 2019;184(2):269-278.

82. Vogel S, Arora T, Wang X, et al. The platelet NLRP3 inflammasome is upregulated in sickle cell disease via HMGB1/TLR4 and Bruton tyrosine kinase. Blood Adv. 2018:2(20): 2672-2680.

83. Davila J, Manwani D, Vasovic L, et al. A novel inflammatory role for platelets in sickle cell disease. Platelets. 2015;26(8):726-729.

84. Vinchi F, Costa da Silva M, Ingoglia G, et al. Hemopexin therapy reverts heme-induced proinflammatory phenotypic switching of macrophages in a mouse model of sickle cell disease. Blood. 2016;127(4):473-486.

85. Dutra FF, Alves LS, Rodrigues D, et al Hemolysis-induced lethality involves inflammasome activation by heme. Proc Natl Acad Sci U S A. 2014:111(39):E4110-4118.
86. Khaibullina A, Adjei EA, Afangbedii N, et al. RON kinase inhibition reduces renal endothelial injury in sickle cell disease mice. Haematologica. 2018;103(5):787-798.

87. Zhao S, Adebiyi MG, Zhang Y, et al. Sphingosine-1-phosphate receptor 1 mediates elevated IL-6 signaling to promote chronic inflammation and multitissue damage in sickle cell disease. FASEB J. 2018;32(5):2855-2865

88. Afrin LB. Mast cell activation syndrome as a significant comorbidity in sickle cell disease. Am J Med Sci. 2014:348(6):460-464.

89. Allali S, Lionnet F, Mattioni S, et al. Plasma histamine elevation in a large cohort of sickle cell disease patients. $\mathrm{Br}$ J Haematol. 2019;186(1):125-129.

90. Brandow AM, Wandersee NJ, Dasgupta M et al. Substance $P$ is increased in patients with sickle cell disease and associated with haemolysis and hydroxycarbamide use. Br J Haematol. 2016;175(2):237-245.

91. Wagner MC, Eckman JR, Wick TM Histamine increases sickle erythrocyte adherence to endothelium. $\mathrm{Br} J$ Haematol. 2006;132(4):512-522.

92. Brooks AC, Whelan CJ, Purcell WM Reactive oxygen species generation and histamine release by activated mast cells: modulation by nitric oxide synthase inhibition Br J Pharmacol. 1999:128(3):585-590.

93. Vincent L, Vang D, Nguyen J, et al. Mast cell activation contributes to sickle cell pathobiology and pain in mice. Blood. 2013;122(11):1853-1862.

94. Amadesi S, Nie J, Vergnolle $\mathrm{N}$, et al. Protease-activated receptor 2 sensitizes the capsaicin receptor transient receptor potential vanilloid receptor 1 to induce hyperalgesia. J Neurosci. 2004:24(18):4300-4312.

95. Kohli DR, Li Y, Khasabov SG, et al. Painrelated behaviors and neurochemical alterations in mice expressing sickle hemoglobin: modulation by cannabinoids. Blood. 2010;116(3):456-465.

96. Stankovic Stojanovic $\mathrm{K}$, Thioliere $\mathrm{B}$ Garandeau E, Lecomte I, Bachmeyer C, Lionnet F. Chronic myeloid leukaemia and sickle cell disease: could imatinib preven vaso-occlusive crisis? $\mathrm{Br} \mathrm{J}$ Haematol. 2011;155(2):271-272.

97. Vang D, Paul JA, Nguyen J, et al. Small-molecule nociceptin receptor agonist ameliorates mast cell activation and pain in sickle mice. Haematologica. 2015;100(12):1517-1525.

98. Navines-Ferrer A, Serrano-Candelas E, Lafuente A, Munoz-Cano R, Martin M Gastaminza G. MRGPRX2-mediated mast cell response to drugs used in perioperative procedures and anaesthesia. Sci Rep. 2018;8(1):11628.

99. Green DP, Limjunyawong N, Gour N Pundir P. Dong X. A mast-cell-specific receptor mediates neurogenic inflammation and pain. Neuron. 2019;101 (3):412-420.

100. Tran H, Mittal A, Sagi V, et al. Mast cells induce blood brain barrier damage in SCD by causing endoplasmic reticulum stress in the endothelium. Front Cell Neurosci. 2019;13:56 